\title{
Neonatal Candida Lusitaniae Septicemia
}

\author{
Gautam MK ${ }^{1}$, Li J ${ }^{2}$
}

\begin{abstract}
Neonatal candidemia is an increasing cause of neonatal morbidity and mortality. Most reported cases are due to Candida albicans, but non-albicans species are on the rise. Candida lusitaniae is infrequently reported opportunistic pathogen. It causes serious and fatal infection. Early diagnosis and proper antifungal therapy can prevent morbidity and mortality in premature neonates.
\end{abstract}

Key words: Candida lusitaniae, Candidemia, Neonatal septicemia

\section{Introduction}

C andida lusitaniae is infrequently reported opportunistic pathogen causing blood stream infection in neonates ${ }^{1}$. It was first described as a common organism in the gastrointestinal tracts of warm-blooded animals ${ }^{2}$. Most of the isolated cases have been resistant to commonly used antifungal Amphotericin $\mathrm{B}^{3}$. Pappagianis et al. ${ }^{4}$ and Holzschu et al. ${ }^{5}$ described the first case of opportunistic infection due to $C$. lusitaniae, reported in a patient with acute leukemia. There are very few articles in the medical literature that report on neonatal candida lusitaniae fungemia. Previously reported cases of serious infection in adults have proven fatal and were associated with amphotericin resistance ${ }^{6}$. We report upon clinical characteristics of two cases of fungal sepsis in the neonatal period caused by C. Iusitaniae in an NICU.

\section{The Cases}

A 25-year-old lady at $31^{+}$5weeks gestation delivered twin babies, first baby 1500 gms female and second 1400 gms male. They were admitted at local neonatal nursery for observation. On the seventh postnatal day, they were referred to our intensive care unit for suspicion of sepsis. On admission, both neonates presented with complaints of poor feeding and lethargy. A soft pan systolic murmur was audible over apical area in the elder twins, which was found to be due to ventricular septal defect $(0.48 \mathrm{~cm})$ by echocardiography. No other abnormal finding except for mild icterus was detected in physical examination in both neonates. During the course of treatment both the neonates underwent nasogastric tube insertion, PICC, CPAP support, broad spectrum antibiotics and parenteral fat emulsions with amino acids and calcium supplementations.
'Dr. Mahesh Kumar Gautam, MBBS, MD Resident, 2Professor Jiang Li, MBBS, MD, PhD, Chief Paediatrician, Both from the Department of Paediatrics, School of Medicine, ZhongDa Hospital, Southeast University, China.

Address for correspondence:

Prof. Dr. Jiang Li

E-mail: jiangli77777@126.com

\section{How to cite}

Gautam MK, Li J. Neonatal Candida Lusitaniae Septicemia. J Nepal Paediatr Soc 2014;34(2):160162.

doi: http://dx.doi.org/10.3126/jnps.v34i2.11161

This work is licensed under a Creative Commons Attribution 3.0 License.

\section{(c) (i)}

During recovery, both developed thermal and hemodynamic instability, bradycardia, respiratory discomfort, feeding intolerance and lethargy. Blood culture was done in addition to PICC tip culture sensitivity, as routine investigation revealed granulocytopenia and increased CRP (C-reactive protein). Candida lusitaniae was isolated in blood culture. It displayed sensitivity to all antifungal drugs including amphotericin B. Both neonates were treated with fluconazole and discharged on $27^{\text {th }}$ day of admission after negative blood culture reports along with drop in CRP level. 
Table 1: Published studies reporting Candida lusitaniae fungemia in neonate

\begin{tabular}{|c|l|c|c|c|}
\hline S.N. & Study & Year & $\begin{array}{c}\text { Isolated Candida } \\
\text { lusitaniae (no.) }\end{array}$ & $\begin{array}{c}\text { Percentage among isolated } \\
\text { Candida species. (\%) }\end{array}$ \\
\hline 1 & Pediatr Infect Dis J. 1992 Oct;11(10):878-80. & 1992 & 1 & NA* \\
\hline 2 & $\begin{array}{l}\text { Pediatrics 2006;117;1680 DOI: 10.1542/peds.2005- } \\
1996\end{array}$ & 2006 & 46 & 2.3 \\
\hline 3 & N Engl J Med, Vol. 345, No. 23December 6, 2001 & 2001 & 5 & 2.28 \\
\hline 4 & Eur J Clin Microbiol Infect Dis. 2002 Apr;21(4):294-9 & 2002 & 1 & NA* \\
\hline 5 & Clinical Infectious Diseases 2003; 36:e14-8 & 2003 & 2 & 1.02 \\
\hline 6 & Diagn Microbiol Infect Dis. 2003 Sep;47(1):331-9. & 2003 & 1 & 0.5 \\
\hline 7 & JAppl Clin Pediatr, VoL 22 No 10 May 2007 & 2007 & 2 & 1.1 \\
\hline 8 & $\begin{array}{l}\text { Journal of clinical Microbiology, Sept. 2008, p. } \\
\text { 2902-2905 }\end{array}$ & 2008 & 2 & 4.8 \\
\hline 9 & J Lab Med Clin, July 2009.Vol 6,No.13 & 2009 & 3 & 1.85 \\
\hline 10 & J Clin. Pediatr Vol.28 No.6 June 2010 & 2010 & 1 & 3 \\
\hline 11 & Mikrobiyol Bul. 2010 Oct;44(4):593-603. & 2010 & 1 & \\
\hline 12 & $\begin{array}{l}\text { International Journal of Pediatrics } \\
\text { Volume 2011, Article ID 813871,6 pages }\end{array}$ & 2011 & 8 & \\
\hline
\end{tabular}

*NA: Not Available

\section{Discussion}

Immaturity of immune system, increased need of interventions and prolonged hospital stay predispose preterm infants to Candida infections. Transmission of Candida may be vertical (from maternal vaginal infection) or nosocomial. Studies including Manzoni et.al have suggested that low birth weight, low gestational age, use of third-generation cephalosporin, endotracheal intubation, duration of stay in the NICU, bacterial sepsis, colonization of central venous catheter, and endotracheal intubation were associated with an increased risk of invasive fungal infections. ${ }^{7}$. This report describes two neonates with serious infections caused by C. Iusitaniae that were successfully treated. During the course of fungemia both neonates became febrile, granulocytopenic with clinical manifestations consistent with serious fungal infection. In each neoante, C. Iusitaniae was isolated from blood only. Although both neonates had indwelling catheters, the catheter tips were negative for culture sensitivity, and were successfully treated without its removal. The possibility of nosocomial transmission was considered since both neonates developed fungemia after 48 hours of hospital admission. No other neonate admitted in the same ward developed fungemia during the same period. The antifungal susceptibility patterns for both isolates were nearly identical. The role of nosocomial transmission in this instance remained speculative.

The clinical characteristics of the neonates reported with C.lusitaniae fungemia were quite similar to those of previously reported patients with C.lusitaniae fungemia. 73 neonatal cases reported in the English or Chinese literature (Table 1). Most of the neonates were VLBW, increasing their susceptibility to C. Iusitaniae fungemia. Most cases reported the use of broad-spectrum antibiotics, intravascular catheter, the use of, and the occurrence of granulocytopenia frequently. Both of the neonates received total parentaral nutrition, a known risk factor for the development of fungemia caused by other Candida species $^{8}$. Both of the neonates had C. Iusitaniae isolated in blood. Resistance to amphotericin B has been an important clinical finding in C. Iusitaniae isolates in adults. On the contrary, isolates in this study were highly sensitive to commonly used antifungal drugs including amphotericin B. Both patients demonstrated a clinical response to therapy.

\section{References}

1. Merz WG. Candida lusitaniae: frequency of recovery, colonization, infection, and amphotericin B resistance. J Clin Microbiol. 1984;20(6):1194-95.

2. Van Uden N, Buckley H. Candida Berkhout. P. In: Lodder J, ed. The yeasts: a taxonomic study. Amsterdam: North-Holland,1970:893-1087.

3. Clancy CJ, Nguyen MH, Yu VL, et al. Fungemia caused by Candida lusitaniae: epidemiology, clinical manifestations, therapy, and outcome. Infect Med 1996;13(940):948-51. 
4. Pappagianis D, Collins MS, Hector R, et al. Development of resistance to amphotericin B in Candida lusitaniae infecting a human. Antimicrob Agents Chemother. 1979;16(2):123-6.

5. Holzschu, D. L., H. L. Presley, M. Miranda, and H. J. Phaff. Identification of Candida liusitnilae as opportunistic yeast in humans. J Clin Microbiol. 1979;10(2):202-5.
6. Blinkhorn RJ, Adelstein D, Spagnuolo PJ. J Clin Microbiol. 1989 Feb;27(2):236-40.

7. Paolo M, Daniele F, MariaLisa L, et al. Risk Factors for Progression to Invasive Fungal Infection in Preterm Neonates With Fungal Colonization. J Pediatrics 2006;118(6):2359-64.

8. Juyal D, Sharma M, Pal S, et.al. Emergence of nonalbicans Candida species in neonatal candidemia. N Am J Med Sci. 2013 Sep;5(9):541-5 